\title{
Micropropagação da bananeira 'Maçã', cultivada in vitro em diferentes volumes de meio líquido
}

\author{
Dalmo Lopes de Siqueira ${ }^{1}$, Dierlei dos Santos ${ }^{2}$, Luiz Carlos Chamhum Salomão ${ }^{1}$, \\ Fabyano Fonseca e Silva ${ }^{3}$, Zoraia de Jesus Barros ${ }^{4}$
}

\section{RESUMO}

Objetivou-se, neste trabalho, avaliar o efeito de diferentes volumes de meio MS líquido estacionário, na taxa de multiplicação e desenvolvimento, in vitro, de explantes da bananeira 'Maçã'. Na etapa de multiplicação, utilizaram-se microrrizomas do cultivar Maçã (AAB), oriundos de plantas pré-estabelecidas em meio sólido, em estádio de multiplicação, que foram uniformizados quanto ao tamanho. O delineamento utilizado foi inteiramente casualizado, com sete tratamentos e dez repetições, sendo a parcela composta por quatro explantes. Os tratamentos foram diferentes volumes de meio líquido estacionário $(5,10,15,20,25,30 \mathrm{~mL}$ ) e $30 \mathrm{~mL}$ de meio semissólido (padrão). Mudas obtidas ao final do terceiro subcultivo foram transferidas para um meio de alongamento e enraizamento. $O$ experimento foi composto pelos mesmos tratamentos e delineamento, sendo cada parcela composta por quatro explantes. Os diferentes volumes do meio líquido e semissólido não alteraram a taxa de multiplicação dos explantes. É possível produzir mudas de bananeira 'Maçã', in vitro, em meio líquido estacionário, sendo o volume ideal de $25 \mathrm{~mL}$ por frasco.

Palavras-chave: multiplicação, desenvolvimento, meios de cultivo, Musa spp.

\section{ABSTRACT \\ Micropropagation of 'Maçã' banana tree, cultivated in vitro in different volumes of liquid medium}

This study aimed to evaluate the effect of different volumes of stationary MS liquid medium on the in vitro multiplication rate and development of banana 'Maçã' explants. During the multiplication phase, were used microrhizome of the cultivar 'Maçã' (AAB), derived from pre-established plants on solid culture medium, which were standardized for size. The experimental design was a completely randomized with seven treatments and ten replicates, and the plot consisted of four explants. The treatments were different volumes of the liquid stationary medium $(5,10$, $15,20,25,30 \mathrm{~mL}$ ) and $30 \mathrm{~mL}$ of semi-solid medium (standard). Microplants produced at the end of the third subculture were transferred to a growth and rooting medium. The experiment consisted of the same treatments and design, and each plot comprises four explants. The different liquid volume and the semi-solid did not alter the explants multiplication rate. It is possible to produce microplants of banana 'Maçã' in vitro in liquid stationary medium, being the optimal volume of the $25 \mathrm{~mL}$ per flask.

Key words: multiplication, development, culture medium, Musa spp.

\footnotetext{
Recebido para publicação em 29/12/2011 e aprovado em 26/09/2013

${ }^{1}$ Engenheiro-Agrônomo, Doutor. Departamento de Fitotecnia, Universidade Federal de Viçosa, Avenida Peter Henry Rolfs, s/n, 36570-000, Viçosa, Minas Gerais, Brasil. siqueira@ufv.br; 1salomão@ufv.br

${ }^{2}$ Engenheiro-Agrônomo, Mestre. Universidade Federal de Viçosa, Avenida Peter Henry Rolfs, s/n, 36570-000, Viçosa, Minas Gerais, Brasil. Bolsista do CNPq. dierlei@ vicosa.ufv.br. (autor para correspondência).

${ }^{3}$ Zootecnista, Doutor. Departamento de Estatística, Universidade Federal de Viçosa, Avenida Peter Henry Rolfs, s/n, 36570-000, Viçosa, Minas Gerais, Brasil. fabyanofonseca@ ufv.br ${ }^{4}$ Engenheira-Agrônoma.. Departamento de Fitotecnia, Universidade Federal de Viçosa, Avenida Peter Henry Rolfs, s/n, 36570-000, Viçosa, Minas Gerais, Brasil. zoraiabarros@ hotmail.com
} 


\section{INTRODUÇÃO}

Um dos principais aspectos que limitam a expansão da bananicultura no Brasil é a utilização de mudas produzidas por meio de métodos convencionais que, além de apresentarem baixa taxa de multiplicação, podem-se constituir num mecanismo de disseminação de pragas e doenças (Roels et al., 2005), ocasionando perdas que podem alcançar $100 \%$ na produtividade, no caso da sigatoka-negra (Silva et al., 2003).

As altas taxas de multiplicação e a qualidade fitossanitária das plantas micropropagadas constituem importante ferramenta para a obtenção massal de clones de genótipos superiores (Kozai et al., 1997), facilitando a distribuição, a conservação e o intercâmbio de germoplasma, além de proporcionar a rápida propagação e validação de variedades recentemente lançadas pelos programas de melhoramento genético da bananeira (Gübbük \&Pekmezci, 2004; Rocha, 2005). Desse modo, é possível também atender, com maior rapidez e eficiência, às necessidades dos produtores.

No Brasil, o uso de mudas micropropagadas para implantação de novas áreas de cultivo tem apresentado crescimento significativo nos últimos dez anos, principalmente, por produtores mais atualizados tecnicamente. Este fato deve-se, principalmente, ao aumento da ocorrência de pragas importantes na cultura da bananeira e à possibilidade de sua disseminação por métodos convencionais de propagação. Aliadas a estes aspectos, existem as exigências de órgãos de fiscalização quanto ao sistema de produção de mudas certificadas (Scherwinski-Pereira et al., 2009).

Plantas micropropagadas sobrevivem mais no campo e crescem mais rapidamente nos primeiros estádios de desenvolvimento, são mais precoces e mais produtivas no primeiro ciclo e proporcionam uniformidade de produção e colheitas superiores às das plantas oriundas de propagação convencional (Teixeira, 2000; Álvares \&Caldas, 2002; Leonel, 2004). Apesar dessas vantagens, as mudas micropropagadas ainda são mais caras que as convencionais (Silva et al.,2005). Altos custos envolvidos com a micropropagação têm dificultado a produção dessas mudas nos laboratórios que possuem recursos limitados (Kodym \&Zapata-Arias, 2001). A utilização de luz natural, em vez da artificial, a substituição de alguns componentes do meio de cultura, como a sacarose, por açúcar comercial, e do Agar, parcialmente, por amido de milho e alguns outros produtos podem reduzir esses custos em até 90\% (Kodym \&Zapata-Arias, 2001; Rocha, 2005).

A consistência do meio de cultura exerce efeito fundamental na morfogênese e no crescimento das brotações, podendo causar sérios transtornos ao desenvolvimento esperado do explante, se as suas exigências básicas não forem atendidas (Karasawa et al., 2002). Os meios podem ser líquidos ou semissólidos. Os meios de cultura líquidos têm proporcionado alta eficiência para a micropropagação de diversas espécies vegetais, como o abacaxi (Escalona et al., 1999; Feuser et al., 2001) e a cana-deaçúcar (Lorenzo et al., 1998). São rapidamente preparados, mais baratos e proporcionam maior homogeneidade, uma vez que a difusão dos componentes do meio é facilitada. No meio semissólido, há diferenças nas quantidades de nutrientes que se estabelecem à medida que os tecidos crescem. A natureza física do meio semissólido possibilita apenas a absorção dos nutrientes pelas partes da planta que estão em contato direto com o meio, refletindo em baixa produção de biomassa (Caldas et al., 1998).

Técnicas que utilizam meio de cultivo líquido com sistema de aeração foram estudadas em bananeiras visando à redução nos custos de produção de mudas micropropagadas. A utilização desse meio de cultivo apresentou vantagens em relação à do meio semissólido (Lemos et al., 2001), porém não se testou essa mesma técnica sem a agitação do meio, importante para fornecer o oxigênio necessário para a respiração do explante (Caldas et al., 1998). Sabe-se que a composição do meio, seu contato com os tecidos e a oxigenação influenciam a habilidade de multiplicação dos explantes (Lemos et al., 1996; Caldas et al., 1998).

Objetivou-se, neste trabalho, avaliar o efeito de diferentes volumes de meio MS líquido estacionário na taxa de multiplicação e desenvolvimento, in vitro, de explantes da bananeira 'Maçã'.

\section{MATERIAL E MÉTODOS}

A pesquisa foi desenvolvida no Laboratório de Cultura de Células e Tecidos Vegetais, do Departamento de Fitotecnia, da Universidade Federal de Viçosa e dividida em duas etapas: etapa de multiplicação e etapa de alongamento e enraizamento.

\section{Etapa de multiplicação}

Utilizaram-se microrrizomas do cultivar Maçã (AAB), oriundos de plantas pré-estabelecidas em meio sólido, em estádio de multiplicação. O delineamento utilizado foi inteiramente casualizado, com sete tratamentos e dez repetições, sendo a parcela composta por quatro explantes. Os tratamentos foram diferentes volumes de meio líquido estacionário $(5,10,15,20,25,30 \mathrm{~mL})$ e $30 \mathrm{~mL}$ de meio semissólido (padrão). O meio utilizado foi o de Murashige \&Skoog (1962), suplementado com 7,0 $\mathrm{mg} \mathrm{L}^{-1}$ de 6- benzilaminopurina (BAP) e $1,0 \mathrm{mg} \mathrm{L}^{-1}$ de ácido naftalenoacético (ANA), $30 \mathrm{~g} \mathrm{~L}^{-}$ ${ }^{1}$ de sacarose, como fonte de carbono, $1 \mathrm{mg} \mathrm{L}^{-1}$ de vitaminas MS, $100 \mathrm{mg} \mathrm{L}^{-1}$ de Myo-inositol e $100 \mathrm{mg} \mathrm{L}^{-1}$ de ácido cítrico para o meio líquido. Para o meio semissólido também foram adicionados $8 \mathrm{gL}^{-1} \mathrm{de}$ ágar Isofarma ${ }^{\circledR}$. 
Após o preparo, os meios líquido e semissólido foram distribuídos em frascos de vidro de $350 \mathrm{~mL}$, com $13 \mathrm{~cm}$ de altura e 6,7 de diâmetro, submetidos à autoclavagem a 121 ${ }^{\circ} \mathrm{C}$ e à pressão de $1,5 \mathrm{~atm}$, por vinte minutos.

Os explantes foram transferidos assepticamente, em câmara de fluxo laminar horizontal, onde receberam limpeza para retirada da parte oxidada e, posteriormente, foram mantidos em condições controladas, com intensidade luminosa de aproximadamente $52 \mu \mathrm{mol} \mathrm{m}{ }^{2}$ s, fotoperíodo de $16 \mathrm{~h} / 8 \mathrm{~h}$ de luz/escuro e temperatura (diurna/notuma) regulada para $27^{\circ} \mathrm{C}$.

Foram realizados três subcultivos com intervalos de 20 dias. Ao final de cada um, foi avaliada a taxa de brotação dos explantes. Os dados foram submetidos à análise de variância, seguida do teste de Dunnett, para comparar os diferentes volumes de meio líquido ao padrão (semissólido), utilizando-se o aplicativo computacional SAS ${ }^{\circledR}$.

\section{Etapa de alongamento e enraizamento}

Mudas obtidas ao final do terceiro subcultivo da etapa de multiplicação foram transferidas para um meio de alongamento e enraizamento. Os meios líquido e semissólido foram preparados com os sais e nutrientes orgânicos do meio MS e suplementados com 1,0 $\mathrm{mgL}^{-1} \mathrm{de}$ BAP, 1,0 mgL-1 ANA, $30 \mathrm{~g} \mathrm{~L}^{-1}$ de sacarose. Ao meio semissólido, foram acrescentados $2,5 \mathrm{~g} \mathrm{~L}^{-1}$ de carvão ativado e $8 \mathrm{~g} \mathrm{~L}^{-1}$ de ágar Isofarma ${ }^{\circledR}$. $\mathrm{O} \mathrm{pH}$ dos meios foi ajustado para 5,7 e as plantas permaneceram por vinte $\mathrm{e}$ dois dias, no meio, até a avaliação.

O experimento foi composto por seis volumes de meio de cultura líquido estacionário $(5,10,15,20,25$ e $30 \mathrm{~mL})$ e o meio padrão (30 mL semissólido). O delineamento adotado foi o inteiramente casualizado, com quatro repetições para os volumes 5 e $10 \mathrm{~mL}$ (líquido) e $30 \mathrm{~mL}$ (padrão), e cinco repetições, para os volumes 15, 20, 25, $30 \mathrm{~mL}$ de meio líquido, sendo cada parcela composta por um frasco contendo quatro explantes. Após o preparo, os procedimentos e recipientes utilizados foram semelhantes aos descritos para a etapa de multiplicação.

As características avaliadas ao final da fase de alongamento e enraizamento foram: Altura da parte aérea (mm): medida tomada da base do pseudocaule até a roseta foliar (inserção da última folha); Diâmetro do pseudocaule (mm): medida tomada na base do pseudocaule, com paquímetro digital; Número de folhas: contagem do total de folhas, por explante; Intensidade da cor verde: medida com o medidor portátil de clorofila SPAD-502 (Soil-Plant Analysis Development), em folha desenvolvida, no ápice de cada planta; Volume do microrrizoma $(\mathrm{mL})$ : determinado pelo volume deslocado de água, após imersão do microrrizoma em uma proveta graduada de $5 \mathrm{~mL}$ com volume conhecido; Massas fresca e seca dos microrrizomas, raízes e parte aérea $(\mathrm{g})$, determinadas por pesagem em balança digital analítica, antes e após secagem, em estufa, com circulação forçada de ar, a $70{ }^{\circ} \mathrm{C}$; Massas fresca e seca total $(\mathrm{g})$ : obtidas pelo somatório das massas do microrrizoma, raiz e parte aérea, antes e após secagem.

Os dados foram submetidos à análise de variância e de regressão e, os modelos escolhidos, baseados na significância dos coeficientes de regressão, utilizando-se o teste "t", a 5\% de probabilidade, no coeficiente de determinação e no fenômeno em estudo. Também foram submetidos ao teste de Dunnett, para comparação dos diferentes volumes de meio líquido com o padrão (meio semissólido), utilizando-se o aplicativo computacional $\mathrm{SAS}^{\circledR}$.

\section{RESULTADOS E DISCUSSÃO}

Não foi verificada diferença significativa, na taxa de multiplicação dos explantes inoculados, entre os diferentes volumes de meio líquido estacionário e o meio semissólido (padrão). Ao final do terceiro subcultivo, obteve-se uma média geral de 1,54 brotos por microrrizoma independentemente dos tratamentos estudados (Tabela 1). Apesar de considerados baixos, esses valores concordam com aqueles obtidos por Sandoval et al. (1991), em estudo em que a taxa de multiplicação de mudas in vitro varia de 1,5 a 3,0, para os cultivares do subgrupo Cavendish. Este fato deve-se, possivelmente, ao acúmulo de BAP no explante (7,0 $\mathrm{mg} \mathrm{L}^{-1}$, em cada subcultivo), cujo excesso inibe a multiplicação (Lima \&Moraes, 2006). A concentração ideal de BAP varia de acordo com o genótipo e as condições de cultivo, situando-se em torno de 2,5 a 5,0 $\mathrm{mg} \mathrm{L}^{-1}$ (Vuylsteke et al., 1988).

Em relação à consistência dos meios, os resultados diferem dos apresentados por Costa et al. (2007), que observaram menor índice de multiplicação no meio líquido estacionário (2,0 brotos/explante), em relação ao meio semissólido (4,8 brotos/explante) no final de três subcultivos do cv. Grand Naine. Domingues et al. (1995), trabalhando com o cv.Maçã, em meio líquido estacionário, encontraram taxas médias de multiplicação de 0,49, inferiores, portanto, às encontradas neste trabalho. Vale salientar que o autor citado utilizou tubos de ensaio com $25 \mathrm{~mL}$ de meio MS líquido. Nesse ambiente, os microrrizomas ficaram completamente mergulhados no meio e, possivelmente, em condições de déficit de $\mathrm{O}_{2}$.

Microplantas propagadas em volumes de meio líquido com 20 e $25 \mathrm{~mL}$ apresentaram maior acúmulo de massa fresca da parte aérea, em relação ao do meio padrão, sendo o máximo atingido quando se utilizou volume próximo a $22 \mathrm{~mL}$ (Figura 1A). Microplantas propagadas em volume de meio líquido de $30 \mathrm{~mL}$ comportaram-se semelhantemente às do padrão, enquanto aquelas mantidas em 5 e $10 \mathrm{~mL}$ foram inferiores. 
Observou-se incremento na altura da parte aérea das microplantas, à medida que aumentou o volume de meio líquido, até o limite de $25 \mathrm{~mL}$, alcançando altura próxima dos $30 \mathrm{~mm}$. Maiores volumes de meio provocaram menor crescimento das microplantas (Figura 1C). Microplantas cultivadas em meio semissólido tiveram crescimento $57 \%$ menor que o daquelas cultivadas em $20 \mathrm{~mL}$ de meio líquido.

Esse maior crescimento das microplantas em meio líquido refletiu-se diretamente na emissão de folhas (Figura $1 \mathrm{D})$. Os tratamentos com 5, 10 e $30 \mathrm{~mL}$ de meio líquido apresentaram comportamento similar ao do tratamento

Tabela 1. Taxa de brotação obtida por explantes de bananeira 'Maçã', cultivados, in vitro, em diferentes volumes de meio MS líquido estacionário comparada ao padrão (MS semissólido)

\begin{tabular}{lcccc}
\hline \multirow{2}{*}{$\begin{array}{l}\text { TRATAMENTOS } \\
(\mathbf{m L})\end{array}$} & \multicolumn{4}{c}{ SUBCULTIVOS } \\
\cline { 2 - 5 } & $\mathbf{1}^{\mathbf{0}}$ & $\mathbf{2}^{\mathbf{0}}$ & $\mathbf{3}^{\mathbf{0}}$ & Média \\
\hline 5 & $1,83 \mathrm{a}$ & $1,73 \mathrm{a}$ & $0,88 \mathrm{a}$ & 1,48 \\
10 & $1,68 \mathrm{a}$ & $1,68 \mathrm{a}$ & $1,05 \mathrm{a}$ & 1,47 \\
15 & $1,25 \mathrm{a}$ & $1,28 \mathrm{a}$ & $0,93 \mathrm{a}$ & 1,15 \\
20 & $2,25 \mathrm{a}$ & $1,73 \mathrm{a}$ & $1,75 \mathrm{a}$ & 1,91 \\
25 & $1,38 \mathrm{a}$ & $1,30 \mathrm{a}$ & $2,15 \mathrm{a}$ & 1,61 \\
30 & $2,00 \mathrm{a}$ & $1,95 \mathrm{a}$ & $1,38 \mathrm{a}$ & 1,78 \\
30 (Semissólido) & $1,50 \mathrm{a}$ & $1,43 \mathrm{a}$ & $1,33 \mathrm{a}$ & 1,42 \\
\hline Média & 1,69 & 1,58 & 1,35 & 1,54 \\
\hline
\end{tabular}

Médias seguidas pela mesma letra na coluna não diferem entre si, a $5 \%$ de probabilidade, pelo teste de Dunnett.

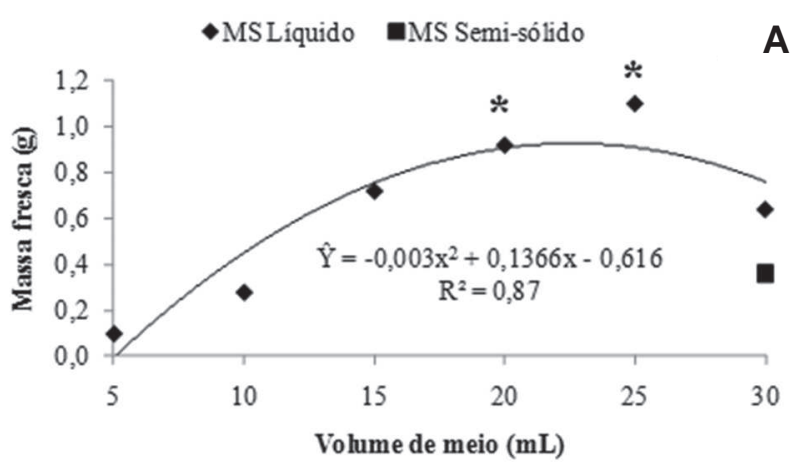

A
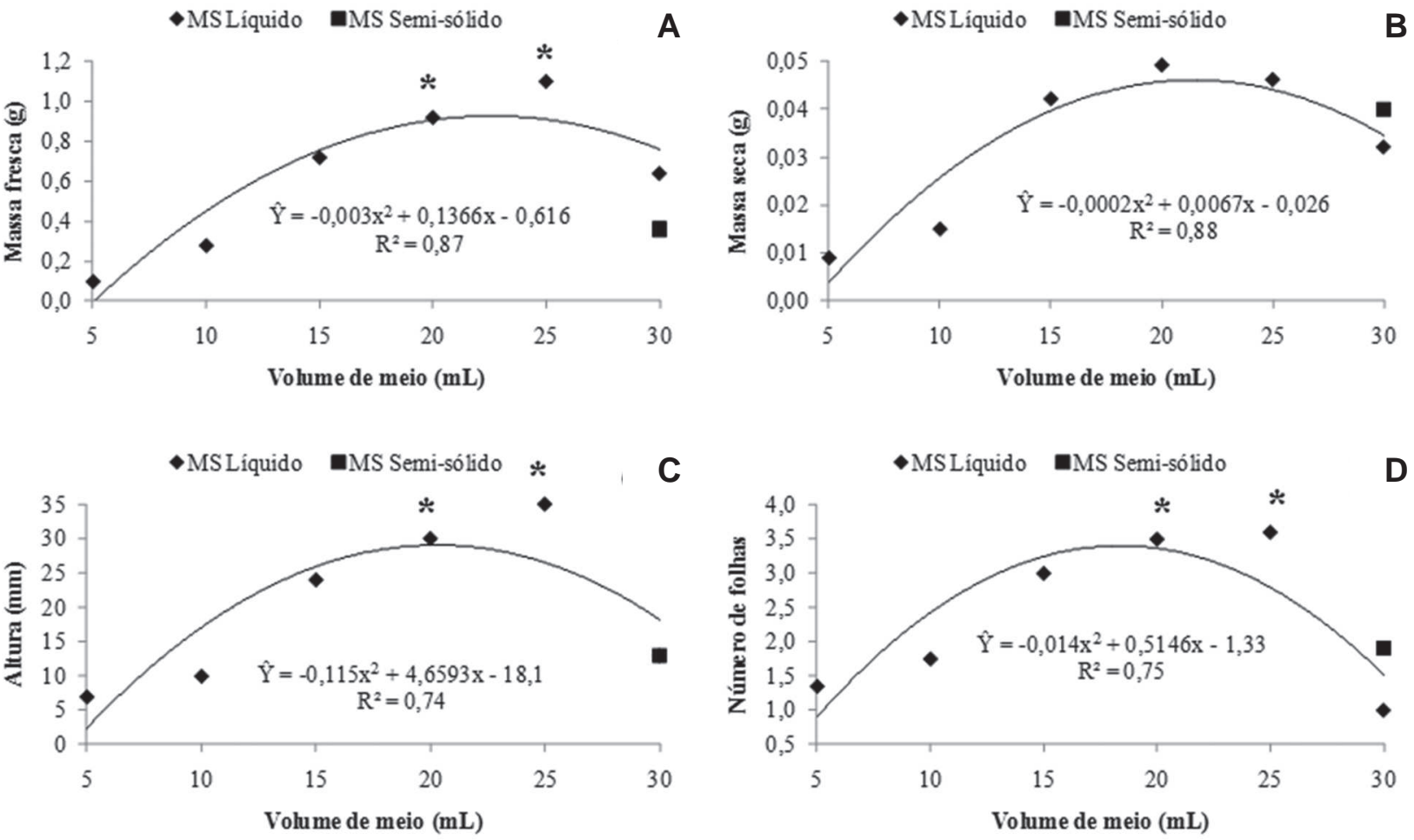

Figura 1. Massa fresca (A), seca (B), altura da parte aérea (C) e número médio de folhas (D) de microplantas de bananeira 'Maçã', cultivadas em diferentes volumes de meio MS líquido estacionário em relação ao padrão (MS semissólido). Médias seguidas de um asterisco (*) diferem do padrão (MS semissólido) a 5\% de probabilidade, pelo teste de Dunnett.

Rev. Ceres, Viçosa, v. 60, n.6, p. 745-751, nov/dez, 2013 padrão (30 mL semissólido). Por outro lado, meios contendo 20 e $25 \mathrm{~mL}$ proporcionaram incremento do número de folhas.

É possível que volumes de meios líquidos situados entre 20 e $25 \mathrm{~mL}$ forneçam a quantidade adequada de nutrientes e que volumes inferiores causem depleção muito rápida. Para o crescimento ótimo das microplantas nesse meio, com pequenos volumes, seria necessária a sua renovação frequente. Por outro lado, em volumes de meio nos quais os explantes ficam praticamente submersos (30 $\mathrm{mL}$ ), a aeração é deficiente, favorecendo o acúmulo de gases prejudiciais ao desenvolvimento das plantas (Lemos et al., 2001).

Para as características massas fresca e seca e volume do microrrizoma (Figuras 2A, B e C), observou-se comportamento linear, em função do aumento do volume de meio líquido. O volume de $30 \mathrm{~mL}$ de meio líquido, para as três características, promoveu incremento das massas fresca , seca e do volume do microrrizoma, de 317, 264 e $280 \%$ respectivamente, em relação aos valores obtidos com o menor volume $(5 \mathrm{~mL})$. Esse incremento foi da ordem de 184,178 e $202 \%$ respectivamente, em relação aos valores obtidos com o meio padrão.

Lemos et al. (2001) verificaram que a utilização de meio líquido, em imersão temporária e estacionária, resultou em melhor aproveitamento do meio de cultura, uma vez que aumentou a área de contato do explante com o meio, do 
qual os nutrientes e água puderam ser absorvidos por todas as partes. Isso se deve à maior facilidade de absorção dos nutrientes e reguladores de crescimento, além da maior relação entre o explante e o meio.

Observou-se que, utilizando-se volume de meio líquido de $20 \mathrm{~mL}$, o diâmetro do pseudocaule de microplantas da 'Maçã' foi máximo, porém, quando o volume líquido foi de $30 \mathrm{~mL}$, a resposta foi inferior e semelhante à do padrão. Volumes de meio líquido inferiores a $20 \mathrm{~mL}$ também proporcionaram menores diâmetros do pseudocaule, assemelhando-se também ao do padrão (Figura 2D).

Verificou-se aumento das unidades SPAD, à medida que aumentou o volume de meio líquido, sendo o máximo atingido com volume próximo a $19 \mathrm{~mL}$ (Figura 2E). Esse efeito pode ser explicado pela maior exposição dos explantes ao meio de cultura líquido, que proporcionou maior assimilação de nutrientes, dentre eles o nitrogênio, resultando em maior concentração de clorofila. A redução das unidades SPAD em volumes superiores a $25 \mathrm{~mL}$ pode
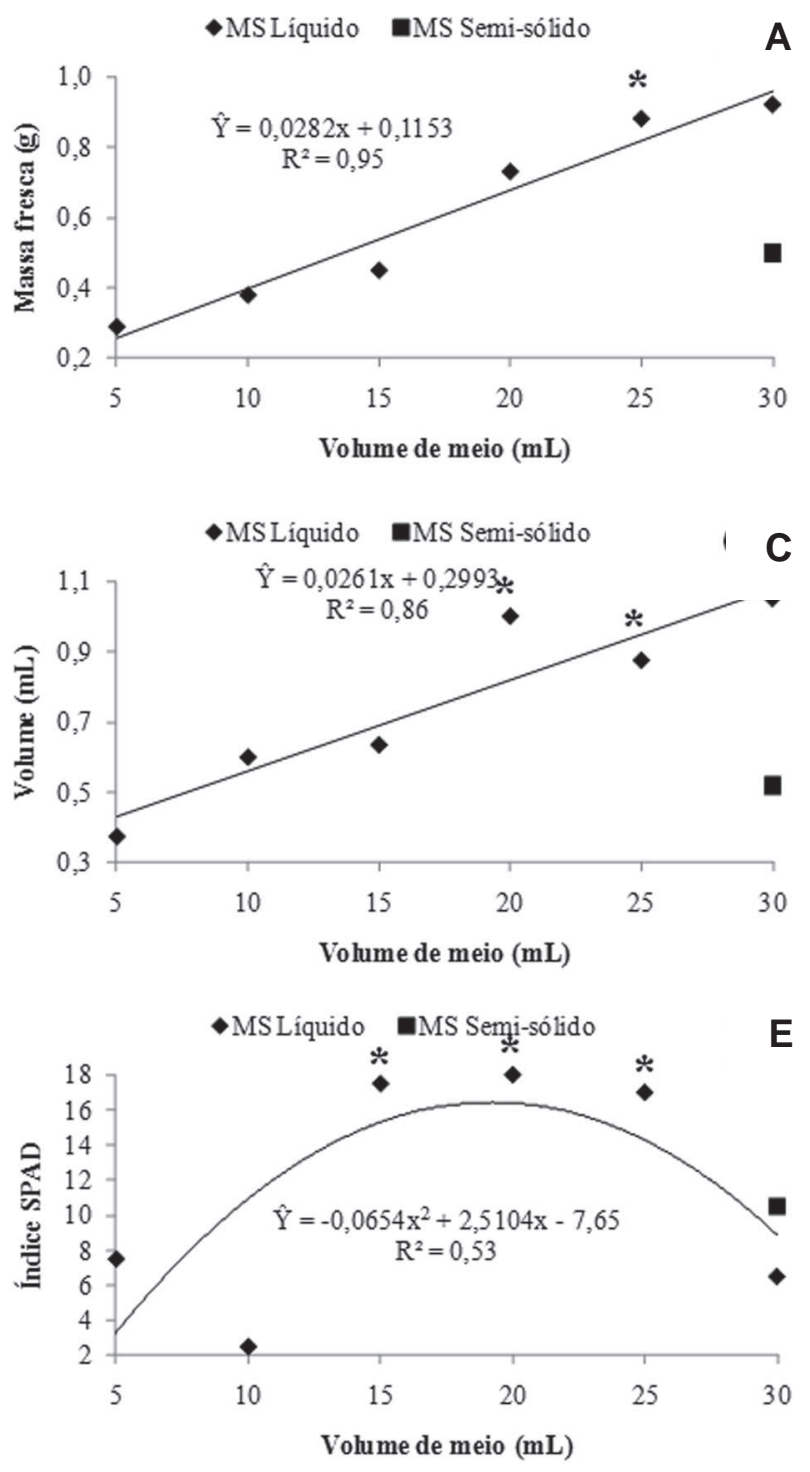

E ser devida à aeração deficiente, que provocou menor absorção de nutrientes. A intensidade da cor verde tem correlação positiva com o teor de clorofila e com a concentração de $\mathrm{N}$ na folha, e essa característica foi verificada em diversas espécies, por diversos autores (Piekielek \&Fox, 1992; Blackrner \&Schepers, 1995; Guimarães et al., 1999; Shapiro, 1999).

Foi verificada influência do meio de cultivo líquido nas massas fresca e seca das raízes (Figura 3A e B). Volumes de meio situados entre 15 e $25 \mathrm{~mL}$ proporcionaram o maior ganho de massa, superando o meio padrão. Por outro lado, volumes de meio líquido iguais ou, inferiores a 10 $\mathrm{mL}$, ou, superiores a $25 \mathrm{~mL}$ apresentaram menor acúmulo de massa.

A porosidade é um dos fatores responsáveis pelo aumento de massa fresca do tecido, uma vez que se acumulam água e oxigênio entre os espaços vazios, resultando em soma de peso. Aguilar et al.(2003), trabalhando com os cultivares Williams e Giant Parfitt (AAA), do subgrupo
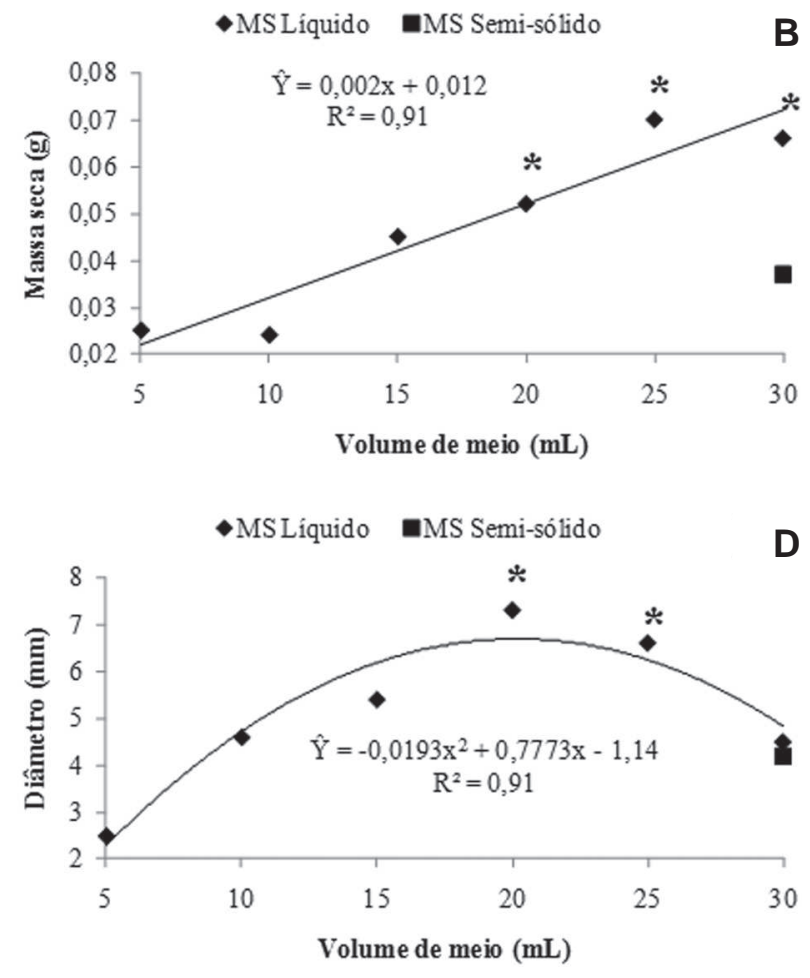

Figura 2. Massa fresca (A), seca (B) e volume do microrrizoma (C), diâmetro do pseudocaule (D) e Intensidade de cor verde (E) (Índice SPAD) de microplantas de bananeira 'Maçã', cultivadas em diferentes volumes de meio MS líquido estacionário em relação ao padrão (MS semissólido). Médias seguidas de um asterisco (*) diferem do padrão (MS semissólido) a 5\% de probabilidade, pelo teste de Dunnett. 
Cavendish, verificaram que, em meio de cultura estacionário, houve um aumento na percentagem de aerênquima dos cultivares trabalhados, que contribui para o ganho de massa.

Foi observado que o aumento no volume de meio proporcionou incremento na massa fresca total de microplantas, até o volume de $25 \mathrm{~mL}$ (Figura 3C), e que esse incremento foi de $195 \%$, em relação ao meio padrão. Uma possível explicação para a sobrevivência dos explantes em meio líquido estacionário é que as bananeiras apresentam

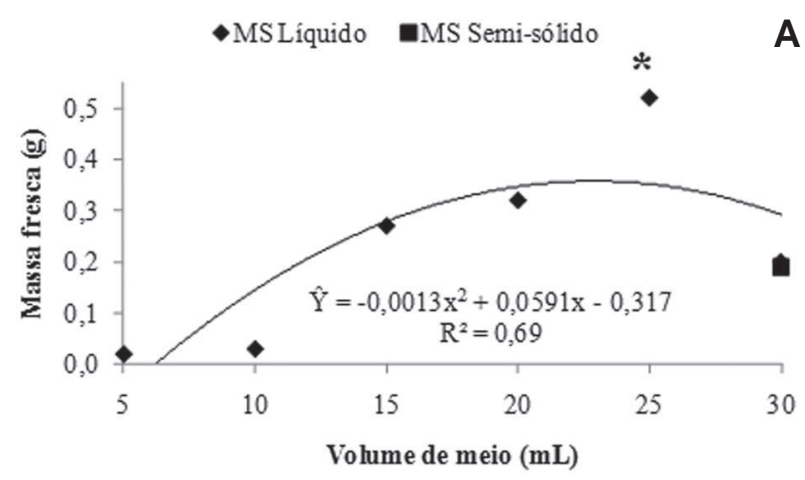

A

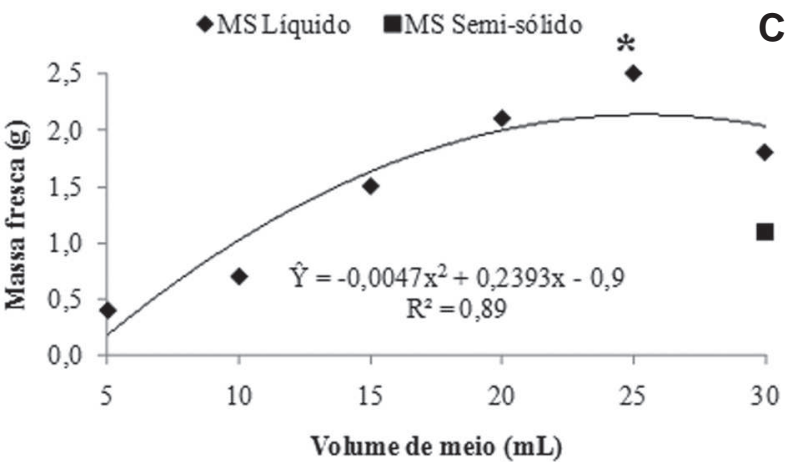

aerênquima, cuja quantidade varia para cada cultivar, em condições de hipoxia. A massa seca total obtida foi $129 \%$ superior à do padrão, quando se utilizou meio líquido que proporcionou resposta máxima (25 mL) (Figura 3D). Quando se utilizou volume igual ou, inferior a $10 \mathrm{~mL}$ de meio líquido, a massa seca total foi inferior ao padrão. Essa redução foi provavelmente devida a uma menor oferta de nutrientes pelos pequenos volumes de meio líquido e, com isso, menor assimilação desses nutrientes (Lemos, et al., 2001).

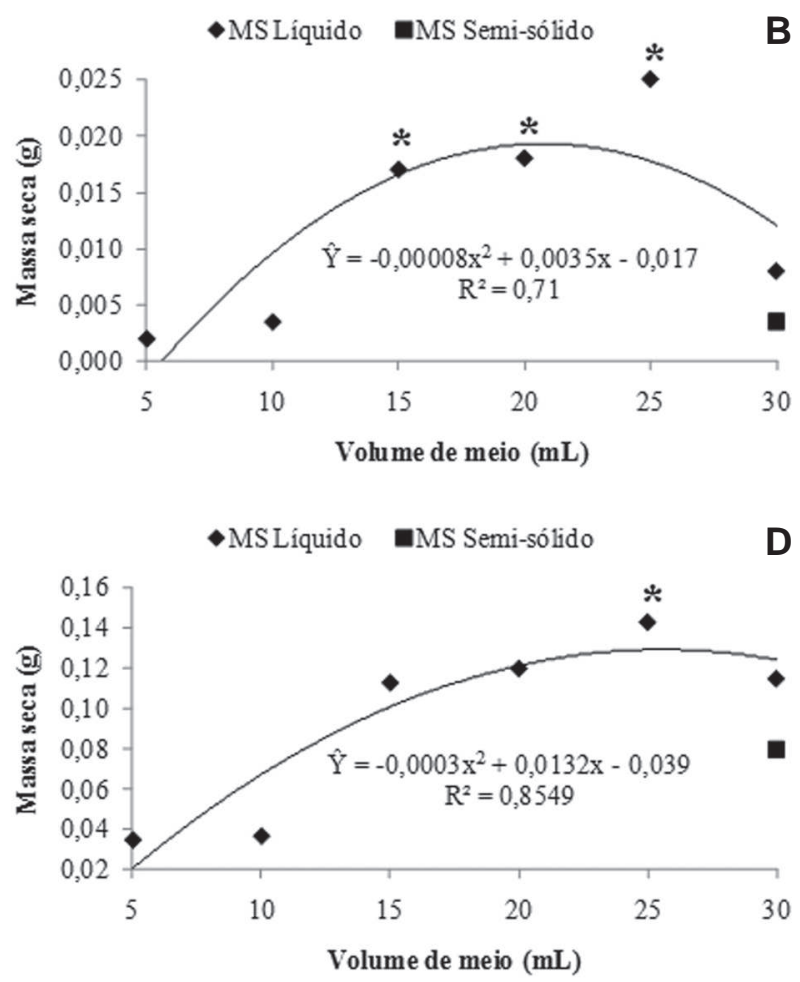

Figura 3. Massa fresca (A) e seca (B) de raízes, massa fresca (C) e seca total (D) de microplantas de bananeira 'Maçã', cultivadas em diferentes volumes de meio MS líquido estacionário em relação ao padrão (MS semissólido). Médias seguidas de um asterisco (*) diferem do padrão (MS semissólido) a 5\% de probabilidade, pelo teste de Dunnett.

\section{CONCLUSÕES}

Os diferentes volumes do meio líquido e do meio semissólido não alteraram a taxa de multiplicação dos explantes.

É possível produzir mudas de bananeira 'Maçã', in vitro, em meio líquido estacionário.

O volume ideal do meio líquido para produzir mudas da bananeira 'Maçã', in vitro, foi de $25 \mathrm{~mL}$ por frasco.

\section{REFERÊNCIAS}

Aguilar EA, Turner DW, Gibbs DJ, Armstrong W \& Snathamparam K (2003) Oxygen distribution and movement, respiration and nutrient and in banana roots (Musassp. L.) subject to aerated and oxygen-depleted environments. Plant and Soil, 253:91-102.
Álvares MC \& Caldas LS (2002) Crescimento, produção e variação somaclonal em bananeiras micropropagadas. Pesquisa Agropecuária Brasileira, 37:415-420.

Blackmer TM \& Schepers JS (1995) Use of a chlorophyll meter to monitor nitrogen status and schedule fertigation for corn. Journal Production Agriculture, 8:56-60.

Caldas LS, Ferreira ME \& Haridasan P (1998) Meios Nutritivos. In: Torres AC, Caldas LS \& Buso JA (Eds.) Cultura de Tecidos e Transformação Genética de Plantas. Brasília, EMBRAPA/CNPH. p.21-43.

Costa FHS, Pereira MAA, Oliveira JPO \& Scherwinski-Pereira JE (2007) Efeito de agentes geleificantes alternativos no meio de cultura no cultivo in vitro de abacaxizeiro e bananeira. Ciência e Agrotecnologia, 31:41-46.

Domingues ET, Tulmann Neto A \& Mendes BMJ (1995) Cultura de ápices caulinares de Musa sp, var. Maçã: estabelecimento, propagação e enraizamento in vitro. Scientia Agrícola, 52:387394.

Rev. Ceres, Viçosa, v. 60, n.6, p. 745-751, nov/dez, 2013 
Escalona M, Lorenzo JC, González B, Daquinta M, González JL, Desjardins Y \& Borroto CG (1999) Pineapple (Ananas comosus L. Merr) micropropagation in temporary immersion systems. Plant Cell Reports, 18:743-748

Feuser S, Nodari RO \& Guerra MP (2001) Eficiência comparativa dos sistemas de cultura estacionária e imersão temporária para a micropropagação do abacaxi. Revista Brasileira de Fruticultura, 23:06-10.

Gübbük H \& Pekmezci M (2004) In vitro propagation of some new banana types (Musa spp.). Turkish Journal of Agriculture and Forestry, 28:355-361.

Guimarães TG, Fontes PCR, Pereira PRG, Alvarez V VH \& Monnerat PH (1999) Teores de clorofila determinados por medidor portátil e sua relação com formas de nitrogênio em folhas de tomateiro cultivado em dois tipos de solo. Bragantia, 58:209-216.

Karasawa MMG, Pinto JEBP, Pinto JC \& Pereira AV (2002) Proliferação de capim elefante em diferentes concentrações de regulador de crescimento e consistências do meio de cultura. $\mathrm{Ci}$ ência e Agrotecnologia, 26:1243-1251.

Kodym A \& Zapata-Arias FJ (2001) Low-cost alternatives for the micropropagation of banana. Plant Cell, Tissue and Organ Culture, 66:67-71

Kozai T, Kubota C \& Byoung RJ (1997) Environmental control for the large scale production of plants through in vitro techniques. Plant Cell, Tissue and Organ Culture, 51:49-56.

Lemos EEP (1996) Experimentos em micropropagação e organogênese na graviola (A. muricata L.). Maceió, EDUFAL. $43 \mathrm{p}$

Lemos EEP, Ferreira MS, Alencar LMC, Oliveira JGL \& Magalhães VS (2001) Micropropagação de clones de banana cv. Terra em biorreator de imersão temporária. Revista Brasileira de Fruticultura, 23:482-487.

Leonel S, Gomes EM \& Pedroso CJ (2004) Agronomic characteristics of micropropagated bananas from Botucatu. Revista Brasileira Fruticultura, 26:245-248.

Lima JD \& Moraes WS (2006) Concentração de Benzilaminopurina e avaliação de protocolo para multiplicação in vitro de genótipos de bananeira. Pesquisa Agropecuária Tropical, 36:13-19.

Lorenzo JC, Gonzales B, Escalona M, Teisson C, Espinosa P \& Borroto CG (1998) Sugar cane shoot formation in an improved temporary immersion system. Plant Cell, Tissue and Organ Culture, 54:197-200.
Murashige T \& Skoog F (1962) A revised mediurn from rapid growth and bioassay with tobacco tissue cultures. Physiologia Plantarum, 15:473-497.

Piekielek WP \& Fox RH (1992) Use of a chlorophyll meter to predict side dress nitrogen requirements for maize. Agronomy Journal, 84:59-65.

Rocha HS (2005) Luz e sacarose na micropropagação da bananeira "Prata Anã": alterações morfoanatômicas. Dissertação de Mestrado. Universidade Federal de Lavras, Lavras. 98p.

Roels S, Escalona M, Cejas I, Noceda C, Rodriguez R, Canal MJ, Sandoval J \& Debergh P (2005) Optimization of plantain (Musa AAB) micropropagation by temporary immersion system. PlantCell, Tissue and Organ Culture, 82:57-66.

Sandoval JA, Brenes G \& Pérez Sánchez L (1991) Micropropagación de plátano y banano (Musa AAB, AAA) en el CATIE. Turrialba, CATIE. 24p. (Informe Técnico, 186).

Scherwinski-Pereira JE, Costa FHS \& Guedes RS (2009) Uso e aplicações biotecnológicas do cultivo in vitro de células, tecidos e órgãos de plantas. In: Gonçalves RC \& Oliveira LC (Eds) Embrapa Acre: Ciência e tecnologia para o desenvolvimento sustentável do Sudoeste da Amazônia. Rio Branco, Embrapa Acre. p.221-246.

Shapiro CA (1999) Using a chlorophyll meter to manage nitrogen applications to com with high nitrate irrigation water. Communications in Soil Science and PlantAnalysis, 30:10371049.

Silva MCA, Tarsitano MAA \& Boliani AC (2005) Análises técnica e econômica da cultura da bananeira 'Maçã' (Musa spp.) na região noroeste do Estado de São Paulo. Revista Brasileira de Fruticultura, 27:139-142.

Silva SO, Gasparotto L, Matos AP, Cordeiro ZJM, Ferreira CF, Ramos MM \& Jesus ON (2003) Programa de melhoramento de bananeira no Brasil - resultados recentes. Cruz das Almas, Embrapa Mandioca e Fruticultura. 36p. (Documentos, 123).

Teixeira LA (2000) Bananeira (Musa spp). In: Meletti LMM (Ed.) Propagação de frutíferas tropicais. Guaíba, Agropecuária. p.105124.

Vuylsteke D, Swennen R, Wilson GF \& De Langhe E (1988) Phenotypic variation among in vitro propagated plantain (Musa sp. cultivar AAB). Scientia Horticulturae, 36:79-88. 